\title{
Benign Oral Masses in a Northern Jordanian Population-a Retrospective Study
}

\author{
Taiseer Hussain Al-Khateeb*
}

\author{
Associate Professor in Oral and Maxillofacial Surgery, Faculty of Dentistry, Jordan University of Science and Technol- \\ ogy, Irbid, Jordan
}

\begin{abstract}
The aim of this study was to evaluate the relative frequencies, types and distribution of benign oral masses in North Jordanians. The records of the Department of Pathology at Jordan University of Science \& Technology were reviewed and analyzed for patients with benign oral soft tissue masses, received during an 11-year period (1991-2001). The main outcome measures were patients' age and sex, and the mass type and location. A sum of 818 benign oral soft tissue masses (4\% neoplastic and $96 \%$ non-neoplastic) was analyzed. Common benign neoplasms were salivary pleomorphic adenoma and lipoma. Non-neoplastic lesions consisted of traumatic (43\%) inflammatory/ infective (33\%), cystic (14\%) and developmental (9\%) lesions. Common non-neoplastic lesions were fibroepithelial polyp, pyogenic granuloma, mucoceles, hemangioma and squamous papilloma, in a descending order. There were 330 (40\%) males and $488(60 \%)$ females with a male to female ratio of $1: 1.5$. The mean age was 33 years, with the majority in the $2^{\text {nd }}, 3^{\text {rd }}$ and $4^{\text {th }}$ decades. The sites commonly affected by benign neoplasms were the palate, tongue, upper lip and buccal mucosa, in a descending order and the sites commonly affected by non-neoplastic lesions were the gingiva, buccal mucosa, lower lip and tongue in a descending order. It is concluded that some of the features of benign oral masses in north Jordanians published in this paper are similar to those from other countries, and some are different. Further nationwide population-based surveys are needed to further define the epidemiology of benign oral masses among Jordanians.
\end{abstract}

Keywords: Benign lesions of the upper aerodigestive tract, Oral cavity tumor, Soft tissue neoplasm, Jordanians.

\section{INTRODUCTION}

The appearance of benign oral soft tissue masses can occasionally resemble malignant tumors. It is, therefore, crucial to distinguish benign from malignant masses, and in order to make a proper diagnosis, the clinical characteristics of benign oral soft tissue masses needs to be well known. Most benign oral soft tissue masses have a specific age and sex distribution and preferable locations in the oral cavity.

Benign oral soft tissue masses encompass a wide variety of mass lesions. Characteristically they all share the property of being exuberant with minimal growth into deeper tissues. These lesions can be either neoplasm or non-neoplasms. Non-neoplastic lesions are usually inflammatory or represent a reaction to some kind of irritation or low-grade injury. Neoplasms on the other hand, represent a process characterized with progressive autonomous growth [1]. Although oral neoplasms can be either benign or malignant, the majority of oral masses have a benign nature. Clinical differential diagnosis of oral lesions is often dependent on obvious changes in color, size, consistency, and relation to neighboring structures. Knowledge of the frequency and distribution of such lesions is also essential when establishing a diagnosis and putting forward a proper treatment plan.

*Address correspondence to this author at the Faculty of Dentistry, Jordan University of Science \& Technology, Irbid, PO BOX 3030, Jordan; Tel: +962-2-7278662-274 (W), +962-2-7243111 (H); Fax: +962-2-7095123; E-mail: Khateeb@just.edu.jo
Despite a considerable volume of literature written about benign oral soft tissue masses in people from different countries, there is very little documentation of the prevalence of such lesions in Jordanians or any other Arab population. The purpose of this retrospective study was, therefore, to analyze the frequency and distribution of the various types of benign oral soft tissue masses found in biopsy specimens taken from northern Jordanians, during an 11-year period starting 1991 and ending 2001.

\section{MATERIALS AND METHODS}

Data included in this retrospective study were collected, by the author, after reviewing all reports from the records of the Department of Pathology at Jordan University of Science $\&$ Technology. The Department of Pathology receives all biopsy specimens, including those from the oral and maxillofacial area, from all hospitals in north Jordan, serving approximately $30 \%$ of the Jordanian population living in four different governorates. The primary source of tissues was from the 6 main hospitals in North Jordan. Biopsies from the oral and maxillofacial area are usually examined and diagnosed by an oral and maxillofacial pathologist. Tumor cases are routinely discussed in scheduled departmental meetings attended by a panel of 4 general pathologists and 2 maxillofacial pathologists. The records of patients with biopsied benign oral soft tissue masses received during an 11-year period from 1991 to 2001, were retrieved, reviewed and analyzed by the authors. For a case to be included the following parameters had be present in the patient's record: age and sex, and the tumors' location and type. Lesions were classi- 
fied according to Scully and Porter [2] into neoplastic and non-neoplastic, and non-neoplastic lesions were further classified into developmental, inflammatory, traumatic and cystic. Data were placed on prepared Microsoft Excel spreadsheets and were evaluated using this software. Patient confidentiality was maintained during this study.

\section{RESULTS}

\section{Types of Swellings}

There were 823 cases of benign oral soft tissue masses, 5 were excluded due to incomplete information and the remaining 818 benign oral soft tissue masses were analyzed. Among these, 36 (4\%) were neoplastic, and 782 (96\%) were non-neoplastic. The tissue of origin of neoplasms was epithelial in $18(50 \%)$ cases and mesenchymal in $18(50 \%)$ cases. Common benign neoplasms were salivary pleomorphic adenoma and lipoma (Table 1).

Non-neoplastic lesions consisted of $336(43 \%)$ traumatic lesions, 257 (33\%) inflammatory/ infective lesions, 110 (14\%) cystic lesions and $73(9 \%)$ developmental lesions. Common non-neoplastic lesions were fibroepithelial polyp, pyogenic granuloma, mucoceles, hemangioma and squamous papilloma, in a descending order (Table 1).

\section{Gender and Age}

Benign oral soft tissue masses included in this series were biopsied from 330 (40\%) males and 488 (60\%) females with a male to female ratio of 1: 1.5. Age ranged from 1 to 93 years (mean of 33 years, standard deviation 19 years). The majority of patients $(59 \%)$ were in their second, third and fourth decades. Fig. (1) shows the distribution of each age group as related to gender. Pleomorphic adenoma was the most common benign neoplasms in all age groups (Table 2). Mucocele was the most common non-neoplastic lesion in the first decade. From the second decade onwards, fibroepithelial polyp was the most common non-neoplastic lesion (Table 2).

\section{Site}

The oral sites commonly affected by benign neoplasms were the palate, tongue, upper lip and buccal mucosa, in a descending order (Table 3). Detailed site distribution of benign neoplasms is shown in Table 3. The sites commonly affected by non-neoplastic lesions were the gingiva, buccal mucosa, lower lip and tongue in a descending order (Table 3). Detailed site distribution of non-neoplastic lesions is shown in Table 3.

\section{DISCUSSION}

Most previous investigations concentrate on studying a single type of benign oral soft tissue masses or a group of closely related ones. This study investigates all benign oral soft tissue masses in a group of Jordanians. The first English-language published review of benign oral soft tissue masses was by Bloodgood [3]. More comprehensive reviews were subsequently published [4-10]. Most of these studies, like the current study, are derived from surgical pathology reports. Such studies admittedly suffer from referral and case selection biases. Nevertheless, information gleaned from these studies is of value for clinicians facing benign oral soft tissue masses on a daily basis. Furthermore, such studies may constitute a base line for future larger-scale investigations. Population-based nationwide investigations among Jordanians are needed to truly describe benign oral soft tissue masses as they occur naturally in life.

We found that the tissue origins of benign oral soft tissue masses were traumatic, inflammatory/ infective, cystic and developmental in descending order. These findings agree with those from other countries [10-12]. Neoplasms constituted $4 \%$ of all benign oral soft tissue masses; this is in general agreement with previous series $[6,10,11]$.

Squamous papilloma was a common benign oral soft tissue masses, its peak incidence was in the 11-30 years age group. This contrasts with the general agreement of its peak of occurrence at 40-60 years of age [13]. We found a slight predilection to male gender which is in agreement with a previous series [14]. The most common location for squamous papilloma was the palate and tongue this also in general agreement with a previous series [14]

The pathogenesis of vascular anomalies is a subject of debate. While some authorities consider them developmental malformations, others consider them as hamartomas of blood vessels. In the present series, one of the most common benign oral soft tissue masses was hemangioma; this is in agreement with previous work $[15,16]$. We also found that the majority of haemangiomas occurred in children and relatively young adults. This finding supports that haemangiomas are developmental in aetiology.

Nearly one tenth of benign oral soft tissue masses reported in this work are of neural origin. Neural origin benign oral soft tissue masses may arise in both soft and hard tissue of the oral cavity. Those occurring in soft tissue appear as smooth sub-mucosal swellings clinically indistinguishable from other benign oral soft tissue masses. One study investigated such a lesion in oral and perioral soft tissues, it was concluded that they are more frequent than previously reported and should be included in the differential diagnosis of the more frequently encountered benign oral soft tissue masses [17].

Fibroepithelial polyp is believed to be a nonspecific focal hyperplastic reaction of the lamina propria of oral mucosa in response to chronic mechanical stimulation. We found that fibroepithelial polyp was the most common benign oral soft tissue masses. This is in agreement with previous findings [4]. Common sites were the buccal mucosa and tongue which also agrees with published literature [4]. Fibroepithelial polyp was almost twice more common in females than males, a finding in agreement previous studies [18], but contrasts with others [4].

Cystic lesions (notably mucoceles) were among the most common non-neoplastic lesions in this series. This agrees with previous series form other countries [7, 19], but conflicts with some others [18]. Mucoceles are common oral lesions since their tissue of origin i.e. salivary glands is widely distributed throughout the oral cavity. We found that the peak incidence is in the first and second decades with lower lip being the most common site. These findings are in agreement with previous work $[4,5]$. Mucoceles were more 
Table 1. Tissue Origin and Type of Benign Oral Soft Tissue Masses and their Gender Distribution

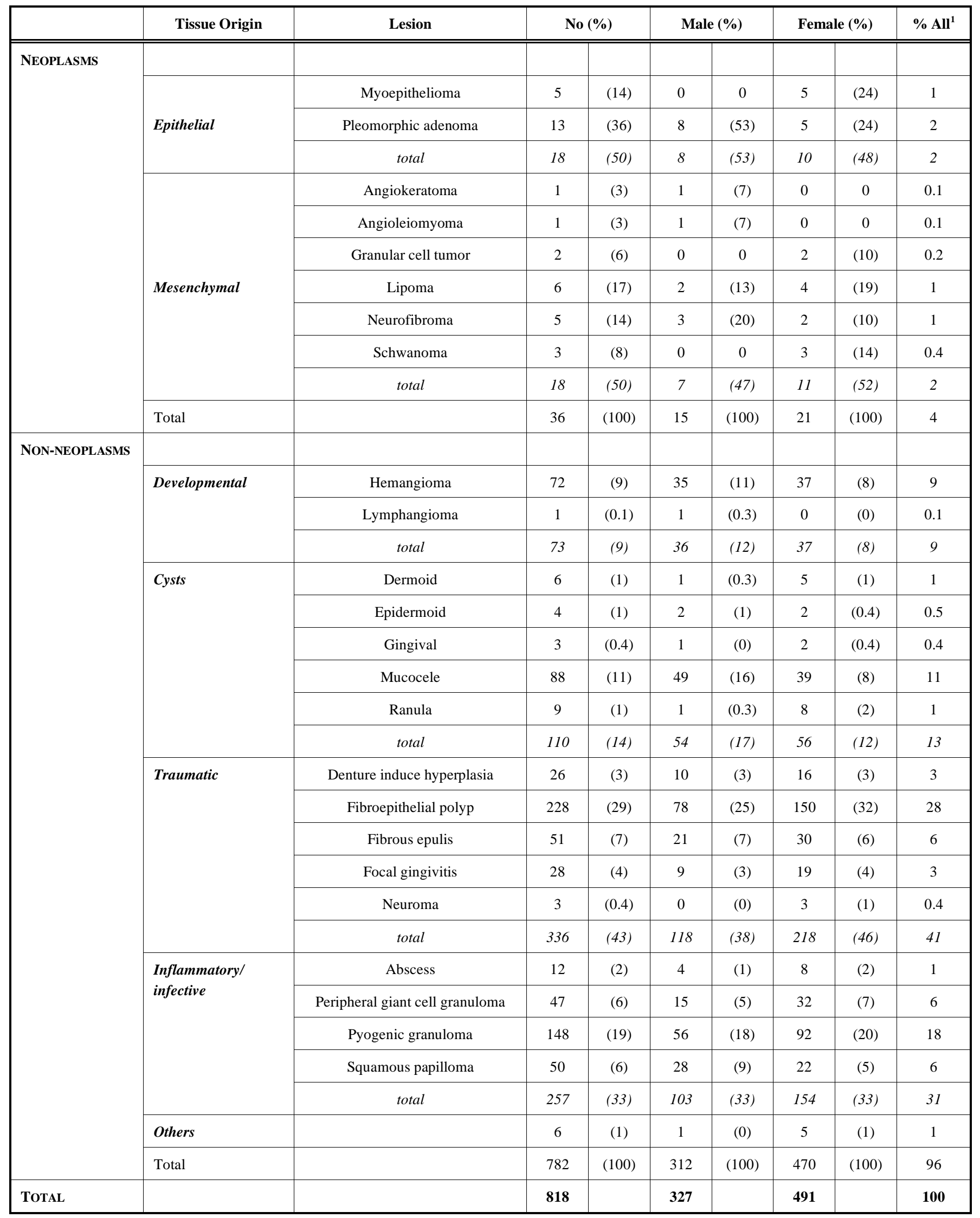

${ }^{1}$ Percentage out of all benign oral soft tissue mass. 


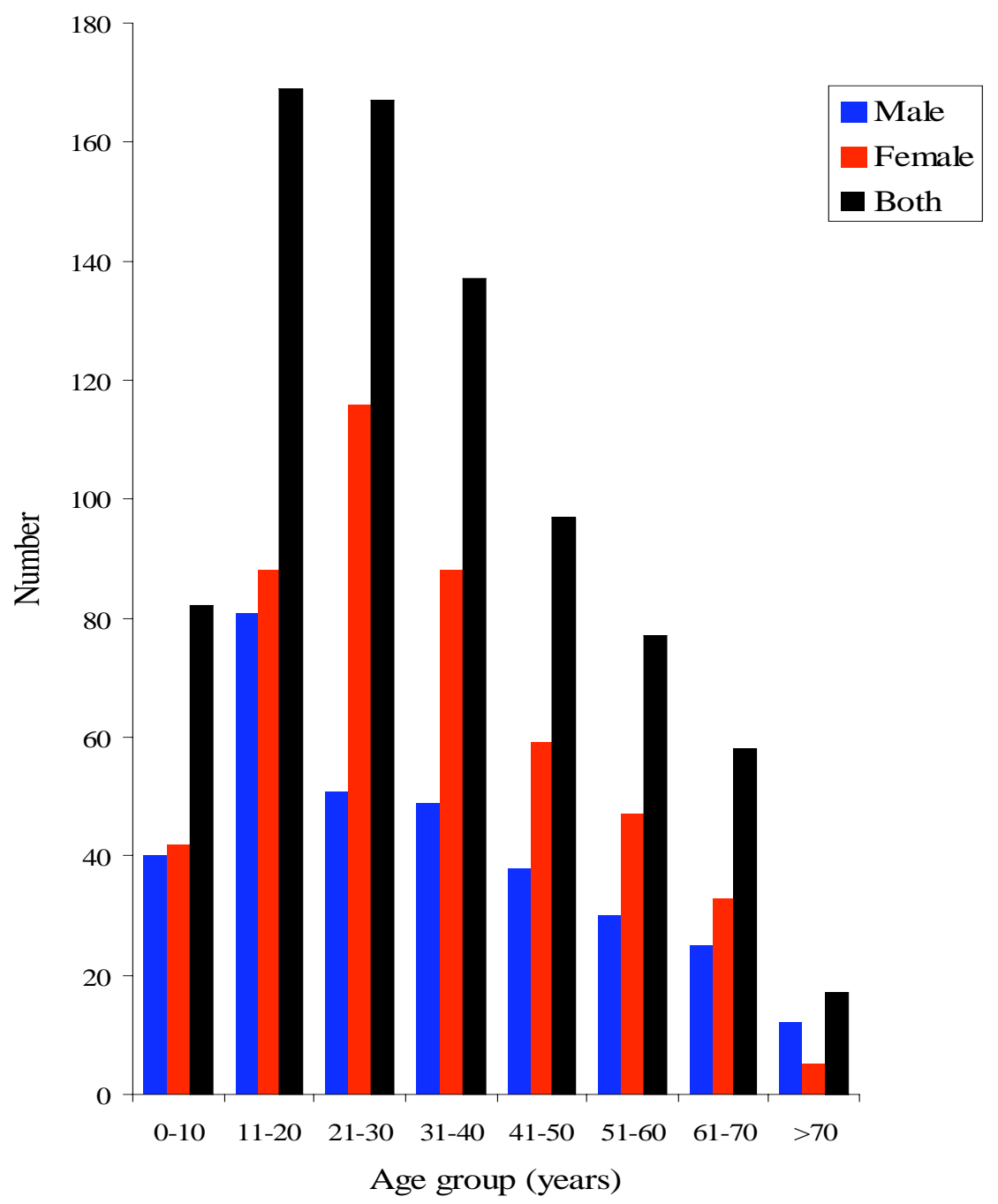

Fig. (1). Age and gender distribution of benign oral masses in Jordanians ( $\mathrm{n}=818$ ).

common among females than males. This agrees with one study [4], but contrasts with another [5].

In our study there was a high degree of occurrence of pyogenic granuloma of the oral cavity in the second, third and fourth decades of life. This age distribution is in accordance with age distribution reported in previous series [2022]. The predominance of pyogenic granuloma among females reported in this series is also in accordance with previous work [20-22]. We found that the principal oral site affected by pyogenic granuloma was the gingiva. These findings are consistent with those of others [21,22].

Benign oral soft tissue masses were more frequent among females, this agrees with others [18], but contrasts with some others [8, 19]. This could reflect differences in the genetic pools between different courtiers. Alternatively, it could reflect different degrees of concern and compliance in females toward dental care between different countries. It has been reported after a longitudinal study of oral hygiene [23] that boys have poorer oral hygiene than girls, and that women, especially the educated, were more frequent dental floss users with a better compliance towards dental advice.

Age at presentation is an important clinical parameter when differential diagnosis of a lesion is being formulated.
The majority of our patients were in their second, third and fourth decades of life. This differs from findings of others who reported a peak incidence from third to sixth decades [10]. This might reflect the high percentage of young people among the Jordanian population. According to the most recent data of the Department of Statistics of Government of Jordan, approximately $60 \%$ of Jordanians are less than 21years of age.

We found that the oral sites commonly affected by benign neoplasms were the palate, tongue, upper lip and buccal mucosa, in a descending order. This is in general agreement with findings of other investigators $[8,10]$. The sites commonly affected by non-neoplastic lesions were the gingiva, buccal mucosa, lower lip and tongue in a descending order. This is in general agreement with findings of some investigators [12] but contrasts with findings of others [4, 8]. These differences are probably related to different methods of categorization of the various benign oral soft tissue masses.

It is concluded that some of our results are in harmony with those of published literature. On the other hand, some of our results are different from published literature. Comparing the overall prevalence rates of the various oral benign oral soft tissue masses between the various published studies 
Table 2. Age Distribution of Benign Oral Soft Tissue Masses

\begin{tabular}{|c|c|c|c|c|c|c|c|c|c|}
\hline \multirow{2}{*}{ Lesion } & \multicolumn{8}{|c|}{ Age Group (Years) } & \multirow{2}{*}{ Total } \\
\hline & $0-10$ & $11-20$ & 21-30 & $31-40$ & $41-50$ & $51-60$ & $61-70$ & $>70$ & \\
\hline \multicolumn{10}{|l|}{ NEOPLASMS } \\
\hline Angiokeratoma & 0 & 1 & 0 & 0 & 0 & 0 & 0 & 0 & 1 \\
\hline Angioleiomyoma & 0 & 0 & 0 & 0 & 0 & 1 & 0 & 0 & 1 \\
\hline Granular cell tumor & 0 & 0 & 2 & 0 & 0 & 0 & 0 & 0 & 2 \\
\hline Lipoma & 0 & 1 & 2 & 3 & 0 & 0 & 0 & 0 & 6 \\
\hline Myoepithelioma & 0 & 2 & 0 & 1 & 0 & 0 & 0 & 2 & 5 \\
\hline Neurofibroma & 1 & 1 & 2 & 0 & 1 & 0 & 0 & 0 & 5 \\
\hline Pleomorphic adenoma & 0 & 4 & 6 & 1 & 1 & 1 & 0 & 0 & 13 \\
\hline Schwanoma & 0 & 2 & 1 & 0 & 0 & 0 & 0 & 0 & 3 \\
\hline Total & 1 & 11 & 13 & 5 & 2 & 2 & 0 & 2 & 36 \\
\hline \multicolumn{10}{|l|}{ NON-NEOPLASMS } \\
\hline Abscess & 1 & 2 & 1 & 6 & 2 & 0 & 0 & 0 & 12 \\
\hline Denture induced hyperplasia & 0 & 0 & 3 & 2 & 3 & 6 & 11 & 1 & 26 \\
\hline Dermoid cyst & 4 & 0 & 0 & 2 & 0 & 0 & 0 & 0 & 6 \\
\hline Epidermoid cyst & 0 & 1 & 1 & 1 & 0 & 1 & 0 & 0 & 4 \\
\hline Fibroepithelial polyp & 9 & 31 & 43 & 47 & 45 & 32 & 17 & 4 & 228 \\
\hline Fibrous epulis & 1 & 15 & 14 & 9 & 7 & 5 & 0 & 0 & 51 \\
\hline Focal hyperplastic gingivitis & 2 & 4 & 6 & 9 & 4 & 2 & 1 & 0 & 28 \\
\hline Gingival & 0 & 0 & 0 & 0 & 0 & 0 & 2 & 1 & 3 \\
\hline Hemangioma & 11 & 18 & 12 & 10 & 2 & 9 & 10 & 0 & 72 \\
\hline Lymphangioma & 1 & 0 & 0 & 0 & 0 & 0 & 0 & 0 & 1 \\
\hline Mucocele & 24 & 31 & 18 & 8 & 4 & 1 & 2 & 0 & 88 \\
\hline Neuroma & 0 & 2 & 0 & 0 & 1 & 0 & 0 & 0 & 3 \\
\hline Others & 0 & 1 & 1 & 2 & 1 & 1 & 0 & 0 & 6 \\
\hline Peripheral giant cell granuloma & 11 & 7 & 7 & 7 & 5 & 5 & 2 & 3 & 47 \\
\hline Pyogenic granuloma & 9 & 33 & 37 & 28 & 15 & 10 & 9 & 7 & 148 \\
\hline Ranula & 5 & 3 & 1 & 0 & 0 & 0 & 0 & 0 & 9 \\
\hline Squamous papilloma & 4 & 12 & 11 & 7 & 8 & 3 & 4 & 1 & 50 \\
\hline Total & 82 & 160 & 155 & 138 & 97 & 75 & 58 & 17 & 782 \\
\hline Total & 83 & 171 & 168 & 143 & 99 & 77 & 58 & 19 & 818 \\
\hline
\end{tabular}


Table 3. Site Distribution of Benign Oral Soft Tissue Masses

\begin{tabular}{|c|c|c|c|c|c|c|c|c|c|c|}
\hline Lesion & Alveolus & $\mathbf{B M}$ & FOM & Gingiva & $\mathbf{L L}$ & Palate & Tongue & $\mathbf{U L}$ & Uvula & Total \\
\hline \multicolumn{11}{|l|}{ NEOPLASMS } \\
\hline Angiokeratoma & 0 & 0 & 0 & 0 & 0 & 0 & 1 & 0 & 0 & 1 \\
\hline Angioleiomyoma & 0 & 0 & 0 & 0 & 0 & 0 & 0 & 1 & 0 & 1 \\
\hline Granular cell tumor & 0 & 0 & 0 & 0 & 0 & 0 & 1 & 1 & 0 & 2 \\
\hline Lipoma & 0 & 3 & 0 & 0 & 1 & 0 & 1 & 1 & 0 & 6 \\
\hline Myoepithelioma & 0 & 0 & 0 & 0 & 0 & 5 & 0 & 0 & 0 & 5 \\
\hline Neurofibroma & 0 & 1 & 0 & 1 & 1 & 0 & 2 & 0 & 0 & 5 \\
\hline Pleomorphic adenoma & 0 & 1 & 0 & 0 & 1 & 8 & 0 & 3 & 0 & 13 \\
\hline Schwanoma & 0 & 0 & 0 & 0 & 0 & 1 & 2 & 0 & 0 & 3 \\
\hline Total & 0 & 5 & 0 & 1 & 3 & 14 & 7 & 6 & 0 & 36 \\
\hline \multicolumn{11}{|l|}{ NON-NEOPLASMS } \\
\hline Abscess & 1 & 3 & 1 & 5 & 2 & 0 & 0 & 0 & 0 & 12 \\
\hline Denture induced granuloma & 23 & 0 & 0 & 2 & & 1 & 0 & 0 & 0 & 26 \\
\hline Dermoid cyst & 0 & 0 & 1 & 0 & 2 & 0 & 0 & 3 & 0 & 6 \\
\hline Epidermal cyst & 0 & 0 & 1 & 0 & 1 & 0 & 1 & 1 & 0 & 4 \\
\hline Fibroepithelial polyp & 2 & 101 & 4 & 11 & 25 & 12 & 63 & 10 & 0 & 228 \\
\hline Fibrous epulis & 0 & 0 & 0 & 51 & 0 & 0 & 0 & 0 & 0 & 51 \\
\hline Gingival cyst & 0 & 0 & 0 & 3 & 0 & 0 & 0 & 0 & 0 & 3 \\
\hline Hemangioma & 0 & 7 & 1 & 5 & 25 & 0 & 17 & 17 & 0 & 72 \\
\hline Hyperplastic gingivitis & 0 & 28 & 0 & 0 & 0 & 0 & 0 & 0 & 0 & 28 \\
\hline Lymphangioma & 0 & 0 & 0 & 0 & 0 & 0 & 1 & 0 & 0 & 1 \\
\hline Mucocele & 3 & 10 & 4 & 0 & 59 & 2 & 10 & 0 & 0 & 88 \\
\hline Neuroma & 0 & 0 & 0 & 0 & 1 & 1 & 0 & 1 & 0 & 3 \\
\hline Others & 0 & 2 & 0 & 1 & 0 & 1 & 1 & 1 & 0 & 6 \\
\hline Peripheral giant cell granuloma & 9 & 0 & 0 & 38 & 0 & 0 & 0 & 0 & 0 & 47 \\
\hline Pyogenic granuloma & 4 & 10 & 0 & 60 & 38 & 5 & 25 & 6 & 0 & 148 \\
\hline Ranula & 0 & 0 & 9 & 0 & 0 & 0 & 0 & 0 & 0 & 9 \\
\hline Squamous papilloma & 1 & 8 & 0 & 0 & 6 & 14 & 12 & 3 & 6 & 50 \\
\hline Total & 43 & 169 & 21 & 176 & 159 & 36 & 130 & 42 & 6 & 782 \\
\hline TOTAL & 43 & 174 & 21 & 177 & 162 & 50 & 137 & 48 & 6 & 818 \\
\hline
\end{tabular}

BM: Buccal Mucosa, FOM: Floor of Mouth, LL: lower Lip, UP: upper Lip. is admittedly complicated due to different ways of categorization, and methodology. Further nationwide populationbased surveys are needed to further define the epidemiology of benign oral soft tissue masses among Jordanians.

\section{REFERENCES}

[1] Boveri T. Concerning the origin of malignant tumours. New York: Cold Spring Harbor Laboratory Press 2008.
[2] Scully C, Porter S. Orofacial diseases: update for the dental clinical team: 5. lumps and swellings. Dent Update 1999; 26: 214-17.

[3] Bloodgood JC. Precancerous lesions of the oral cavity. J Am Dent Assoc 1929; 16: 1353-67.

[4] Bouquot JE, Gundlach KK. Oral exophytic lesions in 23,616 white Americans over 35 years of age. Oral Surg Oral Med Oral Pathol 1986; 62: 284-91.

[5] Kang SK, Kim KS. Clinical and histopathological study of salivary mucoceles. Taehan Chikkwa Uisa Hyophoe Chi 1989; 27: 1059-71. 
[6] Zain RB, Ikeda N, Razak IA, et al. A national epidemiological survey of oral mucosal lesions in Malaysia. Commun Dent Oral Epidemiol 1997; 25: 377-83.

[7] Kovac-Kovacic M, Skaleric U. The prevalence of oral mucosal lesions in a population in Ljubljana, Slovenia. J Oral Pathol Med 2000; 29: 331-5.

[8] Lin HC, Corbet EF, Lo EC. Oral mucosal lesions in adult Chinese. J Dent Res 2001; 80: 1486-90.

[9] Satorres NM, Faura SM, Bresco SM, Berini AL, Gay EC. Prevalence of biopsied oral lesions in a service of oral surgery. Med Oral 2001; 6: 296-305.

[10] Ono Y, Takahashi H, Inagi K, Nakayama M, Okamoto M. Clinical study of benign lesions in the oral cavity. Acta Otolaryngol Suppl 2002; 547: 79-84.

[11] Chen YK, Lin LM, Huang HC, Lin CC, Yan YH. A retrospective study of oral and maxillofacial biopsy lesions in a pediatric population from southern Taiwan. Pediatr Dent 1998; 20: 404-10.

[12] Dimba EA, Gichana J, Limo AK, Wakoli KA, Chindia ML, Awange DO. An audit of oral diseases at a Nairobi centre, 20002004. Int Dent J 2007; 57: 439-44.

[13] Pentenero M, Broccoletti R, Carbone M, Conrotto D, Gandolfo S. The prevalence of oral mucosal lesions in adults from the Turin area. Oral Dis 2008; 14: 356-66.

[14] Anselmi AL, Premoli de Percoco G. Epidemiologic study of 147 cases of oral papilloma. Acta Odontol Venez 1989; 27: 27-32.
[15] Ethunandan M, Mellor TK. Haemangiomas and vascular malformations of the maxillofacial region: a review. Br J Oral Maxillofac Surg 2006; 44: 263-72.

[16] Sato M, Tanaka N, Sato T, Amagasa T. Oral and maxillofacial tumours in children: a review. Br J Oral Maxillofac Surg 1997; 35 92-5.

[17] Williams HK, Cannell H, Silvester K, Williams DM. Neurilemmoma of the head and neck. Br J Oral Maxillofac Surg 1993; 31: 32-5.

[18] Mathew AL, Pai KM, Sholapurkar AA, Vengal M. The prevalence of oral mucosal lesions in patients visiting a dental school in Southern India. Indian J Dent Res 2008; 19: 99-103.

[19] Lawoyin JO. Paediatric oral surgical pathology service in an African population group: a 10 year review. Odontostomatol Trop 2000; 23: 27-30.

[20] Jafarzadeh H, Sanatkhani M, Mohtasham N. Oral pyogenic granuloma: a review. J Oral Sci 2006; 48: 167-75.

[21] Salum FG, Yurgel LS, Cherubini K, De Figueiredo MA, Medeiros IC, Nicola FS. Pyogenic granuloma, peripheral giant cell granuloma and peripheral ossifying fibroma: retrospective analysis of 138 cases. Minerva Stomatol 2008; 57: 227-32.

[22] Lawoyin JO, Arotiba JT, Dosumu OO. Oral pyogenic granuloma: a review of 38 cases from Ibadan, Nigeria. Br J Oral Maxillofac Surg 1997; 35: 185-9.

[23] Addy M, Hunter ML, Kingdon A, Dummer PMH, Shaw WC. An eight-year study of changes in oral hygiene and periodontal health during adolescence. Int J Paediatr Dent 1994; 4: 75-80.

Received: February 23, 2009

Revised: April 09, 2009

Accepted: May 08, 2009

(C) Taiseer Hussain Al-Khateeb; Licensee Bentham Open.

This is an open access article licensed under the terms of the Creative Commons Attribution Non-Commercial License (http://creativecommons.org/licenses/ by-nc/3.0/) which permits unrestricted, non-commercial use, distribution and reproduction in any medium, provided the work is properly cited. 